\title{
Pleidooi voor een stage klinische onderwijskunde binnen de specialistenopleiding
}

\author{
J.C.C. Borleffs, Th.J. ten Cate, C.A.F.M. Bruijnzeel-Koomen, D.W. Erkelens
}

\section{Samenvatting}

Inleiding: Door de veranderingen van onderwijsprogramma's geneeskunde moeten docenten naast vakinhoudelijke kennis beschikken over onderwijskundige vaardigheden. Professionalisering van (klinische) docenten is nodig om de gewenste kwaliteit op het gebied van onderwijs te kunnen garanderen. Voorts is het belangrijk om voor medisch specialisten actieve participatie in het onderwijs aantrekkelijk te maken en de 'concurrentiepositie' van onderwijs ten opzichte van patiëntenzorg en onderzoek te verstevigen. Erkenning en certificering van onderwijskwaliteiten kunnen ertoe bijdragen dat het geven van onderwijs aantrekkelijk is en het carrièreperspectief gunstig beïvloedt.

Binnen de afdeling interne geneeskunde van het Universitair Medisch Centrum Utrecht wil men de arts-assistenten en stafleden die daarin geïnteresseerd zijn, een programma aanbieden om zich op het gebied van onderwijs te kwalificeren. Dit programma sluit aan op de ideeën binnen de beroepsgroep over een stage klinische onderwijskunde als keuzeonderdeel van de specialistenopleiding. Dit artikel is een discussiestuk voor verdere uitwerking van een dergelijke stage door de daarvoor bestaande gremia.

Stage klinische onderwijskunde: De stage duurt maximaal 12 maanden en wordt in deeltijd gelopen, eventueel gecombineerd met andere onderdelen van de specialistenopleiding. De eindtermen zijn ingedeeld in de rubrieken: vakinhoudelijk, algemeen didactisch, ontwerpen van onderwijs, uitvoering van onderwijs, wetenschappelijk onderzoek, toetsen en beoordelen, en andere vaardigheden. Bij aanvang wordt een stageprogramma opgesteld. De arts-assistent heeft regelmatig contact met zijn/haar supervisor en houdt een portfolio bij. De stage bestaat uit uitvoering van onderwijs, cursussen, intervisie/supervisie, het maken van een ontwerp voor onderwijs en een wetenschappelijk product op onderwijskundig gebied. De $k w a l i t e i t s b e o o r d e l i n g$ van de stage geschiedt via de reguliere visitaties van de beroepsvereniging. (Borleffs JCC, Cate ThJ ten, Bruijnzeel-Koomen CAFM, Erkelens DW. Pleidooi voor een stage klinische onderwijskunde binnen de specialistenopleiding. Tijdschrift voor Medisch Onderwijs 2002; 21(1):25-32.)

\section{Inleiding}

Het onderwijs in de geneeskunde is in beweging. In het nieuwe curriculum in Utrecht (CRU'99) zijn zowel de inhoud als de vorm van het onderwijs in belangrijke mate veranderd. ${ }^{1}$ Vergeleken met het 'oude curriculum' is de inhoud zowel meer horizontaal en verticaal geïntegreerd als context(patiënt)gerelateerd, met een sterk accent op attitudevorming en praktische vaardigheden. Daarnaast is er meer gelegenheid voor keuzeonderwijs en wetenschappelijke vorming. Bovendien maakt de opbouw van CRU'99 in het zesde jaar oriëntatie op een specialistische vervolgopleiding mogelijk.

De verandering van de vorm van het onderwijs is mogelijk nog ingrijpender dan die van de inhoud. In CRU'99 ligt de nadruk op kleinschalig onderwijs (werk- 
groepen), zelfstudie (al dan niet gestructureerd) en eigen verantwoordelijkheid van de student voor zijn/haar leerproces. Deze vormen van onderwijs vereisen een grote, wezenlijk andere inzet van docenten dan tot op heden nodig was. Aan de docenten worden hoge eisen gesteld. Docenten moeten niet alleen over vakinhoudelijke kennis beschikken, maar ook over didactische en onderwijskundige vaardigheden. Professionalisering van (klinische) docenten is daarom nodig om de gewenste kwaliteit op het gebied van onderwijs te kunnen garanderen. Het uitgangspunt dat 'onderwijs geven een vak is', is inmiddels algemeen aanvaard. ${ }^{2}$

Binnen de Universiteit Utrecht heeft met de invoering van de regeling Functies Loopbaan en Waardering (FLOW) in 1994 de bevordering van de kwaliteit van docenten aandacht gekregen. In de praktijk biedt deze regeling echter voor medisch specialisten onvoldoende mogelijkheden tot profilering zowel binnen als buiten het Universitair Medisch Centrum (UMC). De geringe waardering voor een functie in het onderwijs en het gebrek aan carrièreperspectief voor specialisten met een onderwijsfunctie maken dat clinici vaak onvoldoende prioriteit geven aan onderwijsactiviteiten in verhouding tot hun werkzaamheden in de patiëntenzorg en het wetenschappelijk onderzoek. Het is daarom niet eenvoudig clinici bereid te vinden tot het leveren van een substantiële bijdrage aan het onderwijs. Om voor medisch specialisten de keuze voor actieve participatie in het onderwijs aantrekkelijk te maken, is het daarom belangrijk dat binnen de beroepsgroep de erkenning van onderwijskwaliteiten duidelijk zichtbaar gemaakt wordt. Voorts dienen onderwijskwaliteiten merkbaar bij te dragen aan de verhoging van de 'marktwaarde' van een specialist. Dat onderwijs ook een gunstig effect heeft op de beroepsuitoefening van de docent, blijkt uit een recent onderzoek onder huisartsen: door het contact met studenten en collegae had het geven van vaardigheidsonderwijs en de daarbij behorende trainingen een duidelijk positief effect op de motivatie van huisartsen. ${ }^{3}$

In dit artikel zetten wij uiteen hoe de erkenning en certificering van onderwijskwaliteiten van klinisch werkzame specialisten kan leiden tot een verbetering van de kwaliteit van het onderwijs. Vanwege de centrale rol die de internist speelt in het onderwijs aan geneeskundestudenten, is ons pleidooi voor een stage klinische onderwijskunde toegespitst op de interne geneeskunde. Een dergelijke stage is echter ook toepasbaar binnen andere specialistische opleidingen. De erkenning dat onderwijs in de loopbaan van de specialist van grote betekenis is, krijgt hiermee een formeel karakter. Iedere specialist, maar in het bijzonder de specialist die werkzaam is in een universitair centrum, heeft op vele momenten te maken met onderwijs: men leert zelf, verzorgt onderwijs, superviseert en is op andere wijzen betrokken bij kennisoverdracht. Dat een zo belangrijk element voor velen slechts 'erbij' komt, doet geen recht aan het grote belang van onderwijs.

\section{Interne geneeskunde en onderwijs}

De afdeling interne geneeskunde is niet alleen in Utrecht maar ook in de curricula van de andere medische faculteiten in Nederland intensief betrokken bij het geneeskundeonderwijs. ${ }^{4}$ Dit geldt voor zowel de inhoudelijke als de uitvoerende aspecten. Deze taken passen bij de plaats die de interne geneeskunde heeft als 'moederspecialisme' binnen de geneeskunde. De afdeling interne geneeskunde draagt daarmee een grote verantwoordelijkheid 
voor de inhoud en de kwaliteit van het onderwijs aan geneeskundestudenten. Dit betekent dat er hoge eisen gesteld worden aan de onderwijsvaardigheden van staf en arts-assistenten van deze afdelingen. Goede dokters zijn echter niet per definitie ook goede docenten. Er bestaan weliswaar 'geboren docenten', maar in het algemeen zal training op dit gebied nodig zijn. Om de motivatie tot het volgen van dergelijke trainingen te vergroten, is erkenning van de verworven kwaliteiten een belangrijke randvoorwaarde.

Binnen de Afdeling Interne Geneeskunde van het UMC is daarom het voornemen om aan arts-assistenten en stafleden die daarin geïnteresseerd zijn, een programma aan te bieden waarmee zij zich op het gebied van onderwijs kunnen kwalificeren. Voor artsassistenten sluit een dergelijk programma aan op de ideeën die bij de beroepsgroep leven over de invulling van de opleiding tot internist. In de voorstellen voor herziene opleidingseisen worden de laatste twee jaren van de opleiding ingevuld met stages naar keuze. Een van de mogelijkheden is een stage klinische onderwijskunde. Voor internisten kan een aanvullend opleidingsprogramma een herkenbare kwalificatie opleveren die in het kader van personeelsbeleid gevolgen kan hebben voor de verdere invulling van hun loopbaan.

\section{Stage klinische onderwijskunde}

\section{Doelstelling en definitie}

De doelstelling van een stage klinische onderwijskunde is om de internist (in opleiding) te trainen kennis en vaardigheden op het gebied van onderwijs toe te passen bij het overdragen van expertise. Die expertise kan in het geval van een internist op het terrein van de interne geneeskunde liggen, maar ook een algemener karakter hebben. De expertise wordt overgedragen aan (geneeskunde)studenten, arts-assistenten of internisten. De stage is bedoeld om kwaliteiten te ontwikkelen en te verwerven die nodig zijn voor het opleiderschap binnen de interne geneeskunde of een van de aandachtsgebieden. Op den duur zou aan het opleiderschap de voorwaarde moeten zijn verbonden dat de betrokkene een stage klinische onderwijskunde heeft gelopen.

Een internist die een stage klinische onderwijskunde heeft afgerond, vormt een brug tussen het werkterrein van de onderwijskundige en dat van de klinisch werkzame specialist. Hij/zij onderscheidt zich met name in het vermogen onderwijskundige inzichten en vaardigheden toe te passen binnen het werkterrein van de klinisch werkzame specialist. Het is daarbij essentieel dat de betrokkene zijn/haar onderwijstaken vervult in combinatie met patiëntenzorgtaken. De stage is een onderdeel van het laatste deel van de opleiding tot internist. De verantwoordelijkheid voor de stage wordt gedeeld door de opleider interne geneeskunde en een apart daartoe te benoemen opleider stage klinische onderwijskunde. Voorts is een nauwe samenwerking met (medisch) onderwijskundigen vereist om de kwaliteit van de onderwijskundige onderbouwing en inhoud van de stage voldoende te garanderen. De expliciete vermelding van de stage als onderdeel van het opleidingsprogramma bij de registratie tot internist maakt dat de verworven ervaring en kwaliteiten op het gebied van onderwijs duidelijk herkenbaar worden.

\section{Eindtermen van de stage}

Figuur 1 geeft een overzicht van de eindtermen die bereikt moeten zijn aan het einde van de stage. De eindtermen kunnen niet los gezien worden van de eindtermen voor het specialisme interne 
Figuur 1. Eindtermen van de stage klinische onderwijskunde toegespitst op het onderwijs aan studenten en arts-assistenten op het gebied van de interne geneeskunde.

\section{Vakinhoudelijk}

- Heeft een gedegen kennis van het vakgebied van de algemene interne geneeskunde en algemene klinische vaardigheden.

- Kan globaal het belang van de interne geneeskunde voor de geneeskundestudie formuleren.

- Kent de plaats van de interne geneeskunde binnen de eindtermen van de geneeskundestudie.

\section{Algemeen didactisch}

- Is aantoonbaar op de hoogte van de onderwijskundige uitgangspunten van de geneeskunde studie en van de opleiding tot internist.

- Kan bepalen welke vorm van sturing studenten en arts-assistenten nodig hebben en deze bieden.

- Kan studenten en arts-assistenten motiveren tot het leveren van studeerprestaties.

- Is op de hoogte van het bestaan van verschillen in leerstijl.

\section{Ontwerpen van onderwijs}

- Kan een cursus of studieonderdeel van het curriculum waaraan vanuit de interne geneeskunde een bijdrage wordt geleverd, ontwikkelen.

- Kan contactonderwijs zinvol inrichten en voorbereiden.

- Kan aan de coördinator van een studieonderdeel feedback geven ter verbetering van het betreffende onderdeel.

- Kan (in voorkomende gevallen) student-assistenten instrueren.

\section{Uitvoering van onderwijs}

- Is op de hoogte van de Onderwijs- en Examenregeling (OER) van het geneeskundecurriculum.

- Is op de hoogte van de Regels en Richtlijnen van de Examencommissie.

- Kan het van hem/haar gevraagde contactonderwijs uitvoeren.

- Kan zijn/haar activiteiten zodanig inrichten dat de meerderheid van de gestelde leerdoelen in de gestelde tijd ook daadwerkelijk wordt bereikt.

- Kan zijn/haar activiteiten zo nodig tussentijds bijstellen.

\section{Wetenschappelijk onderzoek}

- Heeft middels een publicatie, voordracht of congresbijdrage blijk gegeven van wetenschappelijke vaardigheden.

\section{Toetsen en beoordelen}

- Kan een inschatting maken van de voorkennis van een student.

- Kan studenten adequaat beoordelen op grond van niet-schriftelijke prestaties.

- Kan over zijn/haar bijdrage goede toetsvragen maken, richtlijnen geven over wat het goede antwoord moet zijn en toetsvragen nakijken.

\section{Andere vaardigheden}

- Is bereid en in staat tot samenwerking met anderen.

- Is bereid en in staat zich voldoende kennis van en inzicht in de andere vakgebieden die binnen het door hem/haar te begeleiden thema aan de orde komen, eigen te maken.

- Kan het eigen functioneren goed inschatten, mede op basis van evaluatiegegevens en is bereid tot het volgen van trainingen om zijn/haar functioneren te verbeteren.

- Staat open voor veranderingen, houdt zich op de hoogte van vakinhoudelijke ontwikkelingen.

- Heeft oog voor de bewaking en eventuele verbetering van de kwaliteit van het door hem/haar gegeven onderwijs.

- Heeft van studenten of arts-assistenten een goede beoordeling gekregen voor het onderwijs dat hij/zij gegeven of begeleid heeft. 
geneeskunde in Raamplan '94 en de daarop gemaakte aanvullingen. 56 De stage kan dan ook pas worden gelopen als de vier jaar durende basisopleiding van de specialisatie met succes is afgerond.

\section{Programma van de stage}

Het programma is gericht op het realiseren van de in figuur 1 genoemde eindtermen. Omdat de combinatie met patiëntenzorg een voorwaarde voor de stage klinische onderwijskunde is, wordt de stage altijd in deeltijd gelopen en kan deze dus goed gecombineerd worden met andere onderdelen van het programma van de specialistenopleiding. In figuur 2 worden de onderdelen van het programma gepresenteerd. De hierin aangegeven onderdelen van het programma hebben uitsluitend betrekking op de stage klinische onderwijskunde. Aspecten van de patiëntenzorg worden niet expliciet genoemd, omdat wij ervan uitgaan dat die een conditio sine qua non vormen. Tijdens de stage houdt de arts-assistent een portfolio bij waarin zijn/haar vorderingen worden verzameld. Wat betreft de cursussen wordt uitgegaan van het cursusprogramma zoals dat op dit moment door het Onderwijsinstituut van het UMC wordt ontwikkeld. Het is echter ook mogelijk vergelijkbare cursussen van andere instellingen (bijvoorbeeld de Nederlandse Vereniging voor Medisch Onderwijs) te volgen.

Bij de aanvang van de stage wordt aan de hand van een intakeformulier een planning gemaakt van het programma. Tevens wordt daarbij aangegeven welke seniordocent als vaste supervisor zal optreden. Iedere kandidaat heeft minimaal eenmaal per maand een gesprek met de supervisor. De duur van de stage is minimaal zes en maximaal twaalf maanden (gemiddeld 15-20 uur per week gedurende
6 maanden). De planning van de stage moet ter goedkeuring worden voorgelegd aan de opleider stage klinische onderwijskunde en de opleider interne geneeskunde.

\section{Kwaliteitsbewaking stage}

Omdat de stage een onderdeel is van de specialisatie tot internist vindt beoordeling van de kwaliteit plaats via het reguliere systeem van visitatie onder verantwoordelijkheid van de beroepsvereniging (in dit geval de Nederlandsche Internisten Vereeniging). Bij de visitatiecommissie dient dan wel specifieke onderwijskundige expertise aanwezig te zijn.

\section{Slotopmerkingen}

Het is de verwachting dat de behoefte aan internisten met onderwijskundige kwaliteiten zal toenemen door de ontwikkelingen in de onderwijskundige opbouw van de opleiding en ook door het grotere aantal op te leiden artsen en specialisten. ${ }^{7} 8$ De behoefte aan onderwijs beperkt zich echter niet tot de opleiding tot basisarts. Niet alleen in het geneeskundeonderwijs van de medische faculteiten maar ook in vele andere situaties vervullen internisten immers een rol bij het onderwijs en zal de vraag om onderwijskundige professionalisering toenemen. Dergelijke situaties zijn bijvoorbeeld de co-assistentschappen in niet-academische ziekenhuizen, de opleiding tot specialist, nascholing van internisten en andere (para)medische beroepsopleidingen. Met betrekking tot de specialistische beroepsopleiding zijn er recent voorstellen gedaan om ten minste tien procent van de totale duur van de opleiding tot specialist voor (cursorisch) onderwijs te bestemmen. ${ }^{9}$ Voorts wordt in het kader van het kwaliteitsbeleid door de Medisch Specialisten Registratie Commissie en de wetenschappelijke 
Figuur 2. Programma van de stage klinische onderwijskunde.

\begin{tabular}{|c|c|c|}
\hline Stageonderdeel & Toelichting & Omvang* \\
\hline $\begin{array}{l}\text { Uitvoering van } \\
\text { kleinschalig } \\
\text { contactonderwijs }\end{array}$ & $\begin{array}{l}\text { - Onderwijs in kleine groepen, begeleidend en } \\
\text { frontaal (10-12 studenten) } \\
\text { - Bedside teaching } \\
\text { - Begeleiding co-assistenten } \\
\text { (ook vaardigheidsonderwijs geven) }\end{array}$ & $\begin{array}{l}48 \text { uren } \\
10 \text { uren } \\
20 \text { uren }\end{array}$ \\
\hline $\begin{array}{l}\text { Uitvoering van groot- } \\
\text { schalig contactonderwijs }\end{array}$ & $\begin{array}{l}\text { - Hoorcollege } \\
\text { - Werkcollege/practicum } \\
\text { - Patiëntendemonstratie }\end{array}$ & 4 uren (totaal) \\
\hline $\begin{array}{l}\text { Volgen van onderwijs- } \\
\text { kundige cursussen** }\end{array}$ & $\begin{array}{l}\text { - Basiscursus geneeskunde curriculum } \\
\text { - Onderwijs in kleine groepen } \\
\text { - Toetsing } \\
\text { - College/werkcollege } \\
\text { - Patiëntendemonstratie in collegezaal } \\
\text { - Bedside teaching en co-assistentenbegeleiding } \\
\text { - Gebruik van elektronische leeromgeving } \\
\text { - Klinisch Lijn Onderwijs: schrijven van een casus } \\
\text { - Zelfstudie: schrijven en structureren van een } \\
\text { zelfstudieopdracht } \\
\text { - Begeleiding wetenschappelijke stage student }\end{array}$ & Conform cursusduur \\
\hline $\begin{array}{l}\text { Volgen van intervisie/ } \\
\text { supervisie }\end{array}$ & $\begin{array}{l}\text { Parallel aan het geven van klein- en grootschalig } \\
\text { onderwijs; tijdens een van de bijeenkomsten wordt } \\
\text { ten minste eenmaal een video-opname van een half } \\
\text { uur besproken. } \\
\text { - In de laatste } 2 \text { maanden van de stage fungeert de } \\
\text { betrokkene als medesupervisor van jongere collegae } \\
\text { bij de verschillende vormen van onderwijs. }\end{array}$ & $\begin{array}{l}1 \text { uur per } 6 \text { uur } \\
\text { onderwijs }\end{array}$ \\
\hline $\begin{array}{l}\text { Ontwerp maken voor } \\
\text { onderwijs(onderdeel) }\end{array}$ & $\begin{array}{l}\text { - Bijvoorbeeld een studietekst voor het onderwijs of } \\
\text { ander studiemateriaal (video, ICT) }\end{array}$ & Minimaal 1 product \\
\hline $\begin{array}{l}\text { Wetenschappelijk } \\
\text { product }\end{array}$ & $\begin{array}{l}\text { - Bijvoorbeeld publicatie over onderwijs of bijdrage aan } \\
\text { onderwijscongres }\end{array}$ & Minimaal 1 product \\
\hline
\end{tabular}

* exclusief voorbereiding (het aantal uren voorbereiding is in het algemeen 2-3 keer het aantal uren onderwijs)

** de inventarisatie van de cursussen is gebaseerd op het cursusprogramma zoals dat op dit moment in het Onderwijsinstituut van het UMC wordt ontwikkeld. Vergelijkbare cursussen van andere instellingen kunnen ook onderdeel van het programma zijn. 
beroepsverenigingen toenemend belang gehecht aan bijscholing. Dit geeft aan dat de behoefte aan onderwijs door deskundigen binnen de beroepsgroep steeds groter wordt. Een erkende certificering van een stage klinische onderwijskunde als onderdeel van de specialistische opleiding kan een belangrijke bijdrage leveren aan de verbetering van de kwaliteit en het imago van onderwijs als onderdeel van het takenpakket van de toekomstig specialist. De gelijktijdige erkenning van onderwijskundige scholing en training als geaccrediteerde nascholing voor specialisten draagt daar zeker toe bij.

In een in 2000 georganiseerde rondetafelconferentie van internisten(/opleiders) van de acht academische ziekenhuizen is de plaats van de interne geneeskunde in het nieuwe geneeskundeonderwijs uitgebreid aan de orde geweest. ${ }^{4}$ Een belangrijk onderwerp daarbij was een stage klinische onderwijskunde binnen het opleidingsprogramma van de internist. Een verdere uitwerking daarvan werd toen aanbevolen. In dit artikel doen wij daartoe een eerste voorstel. Verder overleg met de daarvoor bestaande gremia is nodig alvorens tot een verdere uitwerking kan worden overgegaan. In dat opzicht moet dit pleidooi als een discussiestuk worden beschouwd.

\section{Literatuur}

1. Borleffs JCC, Daal M, Mulder $\mathrm{H}$, redactie. CRU'99: het nieuwe Utrechtse curriculum. TMO 2001; 20(Supplement):S1-S64.

2. Vries $\mathrm{O}$ de, Keesen F. Professionalisering van docenten. In: Dam GTM ten, et al., redactie.
Onderwijskunde hoger onderwijs. Assen: Van Gorcum \& Comp.; 2000. p. 335-352.

3. Hartley S, Macfarlane F, Gantley M, Murray E. Influence on general practitioners of teaching undergraduates: qualitative study of London general practitioner teachers. Br Med Journal 1999; 319:1168-71.

4. Borleffs JCC, Erkelens DW, Stuyt PMJ. Oog voor de toekomst, het geneeskunde onderwijs in de 21ste eeuw. Medisch Contact 2001; 56:144-7.

5. Metz JCM, Pels Rijcken-van Erp Taalman Kip EH, Brand van den-Valkenburg BWH. Raamplan 1994 artsopleiding, eindtermen van de artsopleiding. Nijmegen: Universitair Publikatiebureau Katholieke Universiteit Nijmegen; 1994.

6. Nederlandse Internisten Vereeniging. Raamplan 2000. Alphen aan den Rijn: Van Zuiden Communications; 2000.

7. Stuyt PMJ. Medisch onderwijs: kwaliteit in balans (oratie). Nijmegen: Katholieke Universiteit Nijmegen; 2001.

8. Velden LFJ van der, Hingstman L, Nienoord-Buré $\mathrm{CD}$, Berg MM van den. De vraag naar artsen becijferd, een prognose van de opleidingscapaciteit 2000-2010. Medisch Contact 2001; 56:446-51.

9. Lange JJ de, Lagaay MB, Hoog JC de. De medisch specialist van morgen. Medisch Contact 2001; $56: 300-2$

De auteurs:

Dr. J.C.C. Borleffs is internist en als directeur CRU'99 (CuRriculum Utrecht '99) lid van het managementteam van het Onderwijsinstituut van het UMC Utrecht.

Prof. dr. Th.J. ten Cate is medisch onderwijskundige en als wetenschappelijk directeur lid van het managementteam van het UMC Utrecht.

Prof. dr. C.A.F.M. Bruijnzeel-Koomen is dermatoloog en manager onderwijs van de Divisie Inwendige Geneeskunde en Dermatologie van het UMC Utrecht.

Prof. dr. D.W. Erkelens is internist en opleider interne geneeskunde in het UMC Utrecht.

Correspondentieadres:

Dr. J.C.C. Borleffs, UMC lokatie AZU, afdeling acute geneeskunde en infectieziekten, Heidelberglaan 100, 3584 CX Utrecht, e-mail j.c.c.borleffs@azu.nl.

\section{Summary}

Introduction: As a consequence of the renovation of undergraduate medical education medical teachers increasingly need didactic skills in addition to their professional clinical skills. Professionalisation of (clinical) teachers is a prerequisite for educational quality. Furthermore, it is important to present clinicians with a more attractive image of teaching bringing it on a more equal footing with patient care and research. Recognition and certification of didactic skills can make teaching more challenging and rewarding, especially if this also means improved career prospects. The Department of Internal Medicine, University Medical Center Utrecht has taken the initiative to offer an internship in 
clinical didactics to its residents and staff members. This internship fits in with national proposals for integrating such a programme into internal medicine residency training. This article is intended as a contribution to the discussions by the appropriate bodies about the introduction of an internship in clinical didactics.

An internship in clinical didactics: The part-time internship lasts no more than twelve months and can be combined with other parts of the residency programme. The objectives fall into the categories discipline-related, general didactic, educational design, teaching, educational research, testing and assessment, and other skills. At the start of the internship an individual programme is designed for the resident. The resident meets regularly with the supervisor and compiles a portfolio. Internship activities comprise: teaching, attending courses, intervision/supervision, developing a teaching activity or teaching material, scientific output in the field of education. Quality assessment of the internship is incorporated into the site visits by the professional association of internists. (Borleffs JCC, Cate ThJ ten, BruijnzeelKoomen CAFM, Erkelens DW. A proposal for the introduction of an internship in clinical didactics into residency training. Dutch Journal of Medical Education 2002; 21(1):25-32.) 